\title{
Functional renal failure and haemorrhagic gastritis associated with endotoxaemia in cirrhosis
}

\author{
C. CLEMENTE' , J. BOSCH, J. RODES, V. ARROYO, A. MAS, AND S. MARAGALL \\ From the Unidad de Hepatología and Servicio de Hemoterapia y Hemostasia, Hospital Clínico y Provincial, \\ Facultad de Medicina de la Universidad de Barcelona, Spain
}

SUMMARY Forty-three patients with cirrhosis and ascites, 21 with normal renal function, 10 with a progressive functional renal failure (FRF), and 12 with a steady FRF, were investigated for the presence of endotoxaemia by the Limulus lysate test. Endotoxaemia was found in nine patients with FRF and in none of the 21 with normal renal function $(P<0.01)$. A positive Limulus test was almost exclusively associated with a progressive FRF (eight of 10 patients) and all but one of them died. Renal function improved as endotoxaemia disappeared in the survivor. Endotoxaemia was also associated with haemorrhage due to acute erosions of the gastric mucosa, being present in six of the seven patients who had this complication. Intravascular coagulation was not found in any patient. The Limulus test was positive in the ascitic fluid in 18 of 21 patients tested, although only two of them had peritonitis. These results suggest that endotoxaemia may play a critical role in the development of progressive renal failure and haemorrhagic gastritis in cirrhosis, and emphasise the potential risk of procedures involving reinfusion of ascitic fluid.

Endotoxin, a lipopolysaccharide derived from Gramnegative microbes, has been shown to have several systemic effects in experimental models, including fever (Greisman and Hornick, 1969), hypotension (Nies et al., 1968), reduction of renal blood flow (Cavanagh et al., 1970), intravascular coagulation (McKay, 1973), and acute erosions in the gastrointestinal tract (Tamakuma et al., 1971).

In the normal man, endotoxin absorbed from the gut into the portal venous blood is rapidly phagocyted by the Kupffer cells (Ravin et al., 1960). This mechanism may be impaired, however, in liver disease, and endotoxin may reach the general circulation and produce several systemic effects. This could be important in some manifestations of Reye's syndrome (Cooperstock et al., 1975) and has been shown to be related to both renal failure and haemorrhagic diathesis in fulminant hepatitis (Wilkinson et al., 1974). The clinical significance of endotoxaemia in cirrhosis has not been extensively studied, although there is evidence indicating that it could occur frequently (Liehr et al., 1975), and its

'Address for reprint requests: C. C., Liver Unit, Hospital Clínico y Provincial, C/Casanova 143, Barcelona, Spain.

Received for publication 3 December 1976 presence has been reported in patients with cirrhosis and renal failure (Wilkinson et al., 1975).

Patients with cirrhosis of the liver are prone to develop severe episodes of gastrointestinal haemorrhage due to acute erosions of the gastric mucosa, and to present a peculiar type of renal failure, characterised by a reduction of the renal plasma flow and the glomerular filtration rate (GFR), a low urinary sodium concentration, a preserved renal concentrating ability, a normal urine sediment, and a poor prognosis (Vesin, 1962; Summerskill, 1966). The absence of substantial evidence of pathological changes in the kidneys of these patients has led to this complication being called 'functional renal failure' of cirrhosis (Vesin, 1962; Lieberman, 1970). In the present study, these serious complications of cirrhosis are associated with the presence of endotoxaemia, as detected by the Limulus lysate assay (Levin and Bang, 1968).

\section{Methods}

Forty-three patients with cirrhosis and ascites were investigated. Twenty-one had a normalrenalfunction, and the other 22 patients were considered to have functional renal failure, as defined by an increased plasma urea concentration, a GFR below $45 \mathrm{ml} / \mathrm{min}$ 
(endogenous creatinine clearance), a urinary sodium concentration below $10 \mathrm{mOsm} / \mathrm{l}$, and a normal urine sediment. Among patients with functional renal failure two different types of evolution were observed. In 10 patients the renal failure followed a rapidly progressive course leading to oligoanuria in a few days (progressive functional renal failure), while in the remaining 12 patients the degree of renal impairment remained steady throughout their stay in hospital, with no trend to progressive deterioration (steady functional renal failure). Thirteen of the 43 patients had a gastrointestinal haemorrhage while in hospital. Emergency endoscopy showed the source of bleeding to be a haemorrhagic gastritis in seven patients, oesophageal varices in five, and duodenal ulcer in one. Biochemical data from the patients are shown in Table 1.

Limulus assay was performed on plasma samples from all the 43 patients and on ascitic fluid of 21 . The amebocyte lysate used in Limulus assay was provided by Mallinckrodt Inc., St Louis, Missouri (lot 4DP). Samples were treated according to Reinhold and Fine (1971). All glassware used was rendered pyrogen-free as described by Yin et al. (1972). Amebocyte lysate $(0 \cdot 1 \mathrm{ml})$ was added to $0 \cdot 1$ $\mathrm{ml}$ of each sample and incubated at $37^{\circ} \mathrm{C}$ for 24 hours. The samples were examined after one, four, and 24 hours of incubation, and the test was considered positive when a definite gelation occurred. The sensitivity of the lysate preparation used allowed endotoxin concentrations above $1 \mathrm{ng} / \mathrm{ml}$ to be detected. In all patients cultures of blood, ascites, and urine were obtained on the day of the endotoxin assay.

The coagulation studies performed in 17 patients included platelet count, prothrombin-time, thrombin time, fibrin degradation products by tanned red blood-cell haemagglutination-inhibition technique, factor V and factor VIII antihaemophilic factor (VIII $\left.{ }_{\mathrm{AHF}}\right)$ by the one-stage method, and factor VIII antigen (VIII ${ }_{\mathrm{AGN}}$ ) by electroimmunodiffusion according to the technique of Laurell (1972).

The statistical significance of differences between means was calculated by Student's $t$ test. The chisquare test (Yates' correction) was used to assess the significance of different incidences of a qualitative variable, unless otherwise specified in the text.

\section{Results}

ENDOTOXAEMIA AND FUNCTIONAL RENAL FAILURE

Nine patients, all from the group of 22 patients with functional renal failure, had a positive Limulus assay. This contrasts sharply with the absence of endotoxaemia among the 21 patients with normal renal function $(P<0.01)$. Only three of the nine patients with a positive Limulus assay had an infection that could be considered to be the source of circulating endotoxin: two had spontaneous peritonitis and one septicaemia, all by Gramnegative organisms. Endotoxaemia was present in eight of the 10 patients with progressive functional renal failure, but in only one of the 12 patients with steady functional renal failure $(P=0.01$, Fisher's exact test). Patients with progressive renal failure had a very poor prognosis. The only survivor of this group was a patient with progressive renal failure associated with endotoxaemia, in whom renal function improved as endotoxaemia disappeared (Figure). No pathological changes were observed in the microscopic examination of the kidneys in those patients who died.

\section{ENDOTOXAEMIA AND GASTROINTESTINAL BLEEDING}

Thirteen of the 43 patients had an episode of gastrointestinal bleeding. Haemorrhage was more frequent in patients with endotoxaemia: seven of the nine patients as compared with six of 34 without endotoxaemia $(P<0.01)$. Endotoxaemia correlated closely with haemorrhage due to acute erosions of the gastric mucosae, being present in six of the seven patients who had this complication as against one of the six patients who bled from other lesions $(\mathrm{P}=$ 0.024, Fisher's exact test). A positive Limulus test

Table 1 Clinical and biochemical data of the three groups of patients

\begin{tabular}{|c|c|c|c|c|c|c|c|c|c|}
\hline Patients studied & $\begin{array}{l}\text { Plasma } \\
\text { urea } \\
(\mathrm{mmol} / \mathrm{l})\end{array}$ & $\begin{array}{l}G F R \\
(\mathrm{ml} / \mathrm{min})\end{array}$ & $\begin{array}{l}\text { Urinary } \\
\text { sodium } \\
(\mathrm{mmol} / 24 h)\end{array}$ & $\begin{array}{l}\text { Bilirubin } \\
(\text { umol/l })\end{array}$ & $\begin{array}{l}\text { Albumin } \\
(g / D)\end{array}$ & $\begin{array}{l}\text { Prothrombin } \\
\text { time } \\
\text { (s prolonged) }\end{array}$ & $\begin{array}{l}\text { Limulus } \\
\text { positive } \\
\text { (no.) }\end{array}$ & $\begin{array}{l}\text { Haemorrhagic } \\
\text { gastritis } \\
\text { (no.) }\end{array}$ & $\begin{array}{l}\text { Death } \\
\text { (no.) }\end{array}$ \\
\hline $\begin{array}{l}\text { Normal renal function } \\
\text { ( } 21 \text { cases) } \\
\text { Steady functional renal failure } \\
\text { ( } 12 \text { cases) } \\
\text { Prooressive functional renal }\end{array}$ & $\begin{array}{r}4 \cdot 78 \\
\pm 0.39 \\
16.04 \\
\pm 1 \cdot 36\end{array}$ & $\begin{array}{r}108 \cdot 2 \\
\pm 8 \cdot 8 \\
36 \cdot 7 \\
\pm 1 \cdot 6\end{array}$ & $\begin{array}{r}30.6 \\
\pm 11.6 \\
6.4 \\
\pm 1.3\end{array}$ & $\begin{array}{c}59 \cdot 85 \\
\pm 15 \cdot 39 \\
34.2 \\
\pm 6.84\end{array}$ & $\begin{array}{r}31 \cdot 9 \\
\pm 1 \cdot 2 \\
31 \cdot 5 \\
\pm 1 \cdot 3\end{array}$ & $\begin{array}{r}2.45 \\
\pm 0.31 \\
2.72 \\
\pm 0.46\end{array}$ & 0 & 1 & $\begin{array}{l}3 \\
4\end{array}$ \\
\hline $\begin{array}{l}\text { Progressive functional renal } \\
\text { failure } \\
\text { (10 cases) }\end{array}$ & $\begin{array}{r}30.67 \\
\pm 5.34\end{array}$ & $\begin{array}{r}12 \cdot 4 \\
\pm 2 \cdot 1\end{array}$ & $\begin{array}{r}3 \cdot 7 \\
\pm 1 \cdot 1\end{array}$ & $\begin{array}{r}160 \cdot 74 \\
\pm 39 \cdot 33\end{array}$ & $\begin{array}{r}28.9 \\
\pm 0.9\end{array}$ & $\begin{array}{r}8 \cdot 75 \\
\pm 1 \cdot 80\end{array}$ & 8 & 6 & 9 \\
\hline
\end{tabular}

Mean \pm SEM. 


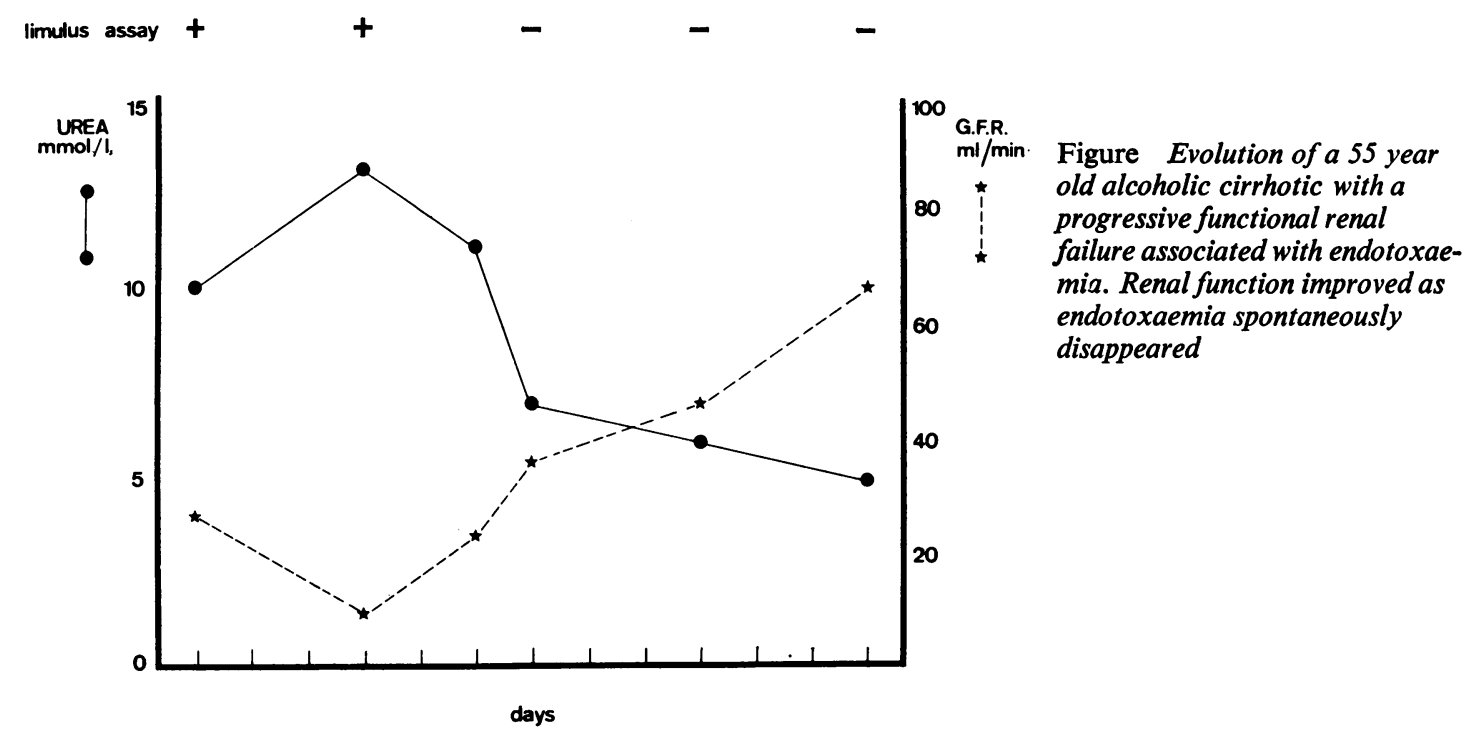

Table 2 Coagulation studies

\begin{tabular}{|c|c|c|c|c|c|c|c|c|}
\hline Patients studied & $\begin{array}{l}\begin{array}{l}\text { Platelet } \\
\text { count }\end{array} \\
\left(\text { no } \times 10^{\circ} / l\right)\end{array}$ & $\begin{array}{l}\text { Prothrombin } \\
\text { time } \\
\text { (s prolonged) }\end{array}$ & $\begin{array}{l}\text { Thrombin } \\
\text { time } \\
\text { (s prolonged) }\end{array}$ & $\begin{array}{l}\text { Plasma } \\
\text { fibrinogen } \\
(g / l)\end{array}$ & $\begin{array}{l}\text { Fibrin } \\
\text { degeneration } \\
\text { products } \\
(u g / m l)\end{array}$ & $\begin{array}{l}\text { Factor } V \\
\text { activity } \\
(u / m l)\end{array}$ & $\begin{array}{l}F . V I I I_{\mathrm{AHF}} \\
\text { activity } \\
(u / m l)\end{array}$ & $\begin{array}{l}F . V_{\text {VIII }} \mathrm{AGN} \\
\text { activity } \\
(u / m l)\end{array}$ \\
\hline $\begin{array}{l}\text { Normal range } \\
\text { Endotoxin-positive } \\
\text { (6 cases) }\end{array}$ & $100-300$ & $13 \pm 1$ & $20-25$ & $2-4$ & 16 & $0 \cdot 75-1 \cdot 20$ & $0 \cdot 5-1 \cdot 5$ & $0 \cdot 5-1 \cdot 5$ \\
\hline $\begin{array}{l}\text { Mean } \\
\text { SEM } \\
\text { Endotoxin-negative } \\
\quad \text { (11 cases) }\end{array}$ & $\begin{array}{r}143 \cdot 3 \\
39 \cdot 3\end{array}$ & $\begin{array}{l}8.00 \\
1.63\end{array}$ & $\begin{array}{l}4.2 \\
2.0\end{array}$ & $\begin{array}{l}2.5 \\
0.2\end{array}$ & $\begin{array}{r}10 \cdot 0 \\
2.0\end{array}$ & $\begin{array}{l}0.47 \\
0.14\end{array}$ & $\begin{array}{l}1.52 \\
0.28\end{array}$ & $\begin{array}{l}4.93 \\
0.87\end{array}$ \\
\hline $\begin{array}{l}\text { Mean } \\
\text { SEM } \\
\text { P value* }\end{array}$ & $\begin{array}{l}86.5 \\
17 \cdot 0 \\
\text { NS }\end{array}$ & $\begin{array}{r}4.13 \\
0.64 \\
<0.02\end{array}$ & $\begin{array}{l}4 \cdot 6 \\
1 \cdot 2 \\
\text { NS }\end{array}$ & $\begin{array}{l}2 \cdot 7 \\
0 \cdot 4 \\
\text { NS }\end{array}$ & $\begin{array}{l}9 \cdot 81 \\
1 \cdot 56 \\
\text { NS }\end{array}$ & $\begin{array}{l}0.31 \\
0.04 \\
\text { NS }\end{array}$ & $\begin{array}{l}1 \cdot 29 \\
0 \cdot 21 \\
\text { NS }\end{array}$ & $\begin{array}{l}5 \cdot 64 \\
0 \cdot 48 \\
\text { NS }\end{array}$ \\
\hline
\end{tabular}

*P values compare the differences between endotoxin-positive and negative patients.

NS = no significant difference.

was frequently associated with both progressive renal failure and haemorrhagic gastritis. This association occurred in six patients.

\section{COAGULATION STUDIES}

Results of coagulation studies in patients with and without endotoxaemia are shown in Table 2. No significant differences were found between the two groups of patients except for a more prolonged prothrombin time in patients with endotoxaemia $(P<0.02)$. No patient showed clinical signs suggesting an active intravascular coagulation. All had a very high level of factor VIII $_{A G N}$.

ENDOTOXIN IN ASCITES

The presence of endotoxin in the ascitic fluid was investigated in 21 patients. Eighteen gave a positive result. The simultaneously performed ascitic fluid culture was positive in only two of these 18 patients, who also had clinical signs of peritonitis. Endotoxin was detected both in ascites and peripheral blood in only seven patients, and, in them, the concentration of endotoxin in the ascitic fluid was higher than in the 11 patients without endotoxaemia, as indicated by an earlier appearance of gelation.

\section{Discussion}

Endotoxaemia has been shown to be related to renal failure, intravascular coagulation, and haemorrhagic manifestations in fulminant hepatic failure (Wilkinson et al., 1974). In the present study a close cor- 
relation between endotoxaemia and the appearance of progressive renal failure and gastrointestinal haemorrhage from acute erosions of the gastric mucosa was reported in patients with cirrhosis of the liver. However, the nature of the present investigation did not allow us to draw definite conclusions about whether this was a causal relationship or whether they were parallel manifestations of advanced liver failure. Nevertheless, there was experimental evidence of a cause-and-effect relationship between the presence of circulating endotoxin, impairment of renal function, and the development of gastrointestinal haemorrhage. Cavanagh et al. (1970) showed that the administration of endotoxin to the primate provokes a rise in renal vascular resistance and a reduction of renal blood flow. Tamakuma et al. (1971) presented evidence that endotoxaemia may produce acute erosions in the gastrointestinal tract in rabbits. On the other hand, the incidence of gastrointestinal bleeding in the course of septic shock and in systemic infections due to Gram-negative organisms in man is higher than in infections by Gram-positive organisms (Altemeier et al., 1972), and this has been considered to be an endotoxin-related effect.

Functional renal failure in cirrhosis has been regarded as a rapidly progressive complication with a fatal outcome (Summerskill, 1966), and its appearance has been related to other complications of liver disease, such as haemorrhage or infections, even though, in some cases, no precipitant factors could be found (Summerskill, 1966; Conn, 1973). Recently, Lieberman (1970), Bosch (1973), and Rodés et al. (1975) have stressed that patients with cirrhosis and ascites frequently exhibit moderate degrees of renal failure for long periods. Survival of patients with this steady type of functional renal failure is significantly higher than in the classical progressive form. In a recent series, a $50 \%$ mortality was reached only after 11 months of follow-up (Rodés et al., 1975).

In this study, endotoxaemia was found in almost all patients with progressive functional renal failure. On the contrary, only one of the 12 patients with steady functional renal failure and none of the 21 patients with normal renal function had detectable levels of circulating endotoxin. These results suggest that endotoxaemia may play an important role in the appearance of progressive renal failure in cirrhosis with ascites. The failure to detect endotoxaemia in the 'steady' group could be due to the Limulus assay not being sensitive enough to detect very small quantities of circulating endotoxin, although it cannot be excluded that in these patients the renal failure is not related to endotoxaemia. The relationship between endotoxaemia and progressive functional renal failure is emphasised by the progress of the only patient in this series with progressive renal failure who survived, in whom renal function improved as endotoxaemia disappeared (Figure). A spontaneous improvement of functional renal failure in cirrhosis is observed in a few patients (Goldstein and Boyle, 1965; Conn, 1973), generally with an improvement in the underlying liver disease.

In this study, endotoxaemia was also associated with gastrointestinal bleeding due to haemorrhagic gastritis. Six of the seven patients with this complication had a positive Limulus test. The pathogenesis of haemorrhagic gastritis remains obscure, but it was not apparently related to intravascular coagulation. In fact, the coagulation studies disclosed no signs of overt intravascular coagulation in any patient, whether endotoxaemia was present or not. The only difference between endotoxin-positive and negative patients was a moreprolonged prothrombin time in the former, which in the absence of signs of increased peripheral consumption should be ascribed to a worse liver function. All patients had very high

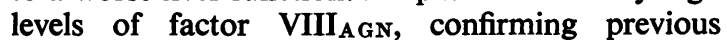
reports in patients with cirrhosis (Green and Ratnoff, 1974). This has not been adequately explained, and the results of the present study suggest that this is not related to an incapacity of the liver to clear circulating endotoxins.

In the absence of overt infection, as was the case in two-thirds of our patients with endotoxaemia, the most likely source of endotoxin is absorption of that produced by enteric organisms. In normal conditions (Ravin et al., 1960) endotoxin is absorbed from the gastrointestinal tract via the portal vein and completely cleared from the blood by the reticuloendothelial cells in the liver (Braude et al., 1955). Portosystemic shunting in cirrhosis may allow endotoxin to reach the general circulation. On the other hand, there is experimental evidence indicating that, when a venous outflow block is produced in an intestinal loop, endotoxin rapidly diffuses through the intestinal wall (Nolan and Ali, 1972). It is possible that portal hypertension could act in a similar way, favouring the passage of endotoxin either into the portal venous radicles or directly into the peritoneal cavity, thus explaining our finding of endotoxin in ascites in many patients, even in 11 who did not have detectable endotoxaemia. An alternative way by which endotoxin may reach the ascitic fluid could be that some of the endotoxin present in the portal venous blood subsequently overflows into ascites.

The finding of endotoxin in ascites may raise several theoretical objections about the safety of some procedures currently used in clinical practice, involving the infusion of ascitic fluid. In fact, some 
of the complications observed during ascitic fluid reinfusion, such as pyrexia and gastrointestinal haemorrhage (Parbhoo et al., 1974; Levy et al., 1975), may be related to endotoxin.

The authors are indebted to Dr M. Bruguera for his help and criticisms in the preparation of the manuscript, to Dr J. Terés for allowing us to investigate patients under his care, and to Dr J. M. Bordas, who performed the emergency endoscopies.

\section{References}

Altemeier, W. A., Fullen, W. D., and McDonough, J. J. (1972). Sepsis and gastrointestinal bleeding. Annals of Surgery, 175, 759-770.

Bosch, J. (1973). Tipos de Insuficiencia Renal Asociados a la Cirrosis Hepática. Thesis: University of Barcelona.

Braude, A. I., Carey, F. J., and Zalesky, M. (1955). Studies with radioactive endotoxin. II. Correlation of physiologic effects with distribution of radioactivity in rabbits injected with lethal doses of $E$. coli endotoxin labelled with radioactive sodium chromate. Journal of Clinical Investigation, 34, 858-866.

Cavanagh, D., Rao, P. S., Sutton, D. M. C., Bhagat, B. D., and Bachmann, F. (1970). Pathophysiology of endotoxin shock in the primate. American Journal of Obstetrics and Gynecology, 108, 705-722.

Conn, H. O. (1973). A rational approach to the hepatorenal syndrome. Gastroenterology, 65, 321-340.

Cooperstock, M. S., Tucker, R. P., and Baublis, J. V. (1975). Possible pathogenic role of endotoxin in Reye's syndrome. Lancet, 1, 1272-1274.

Goldstein, H., and Boyle, J. D. (1965). Spontaneous recovery from the hepatorenal syndrome. New England Journal of Medicine, 272, 895-898.

Green, A. J., and Ratnoff, O. D. (1974). Elevated antihemophilic factor (AHF, factor VIII) procoagulant activity and AHF-like antigen in alcoholic cirrhosis of the liver. Journal of Laboratory and Clinical Medicine, 83, 189-197.

Greisman, S. E., and Hornick, R. B. (1969). Comparative pyrogenic reactivity of rabbit and man to bacterial endotoxin. Proceedings of the Society for Experimental Biology and Medicine, 131, 1154-1158.

Laurell, C.-B. (1972). Electroimmuno assay. Scandinavian Journal of Clinical Laboratory Investigation, suppl., 124, 21-37.

Levin, J., and Bang, F. B. (1968). Clottable protein in Limulus: its localisation and kinetics of its coagulation by Endotoxin. Thrombosis et Diathesis Haemorrhagica, 19, 186-197.

Lévy, V. G., Opolon, P., Pauleau, N., and Caroli, J. (1975). Treatment of ascites by reinfusion of concentrated peri- toneal fluid. Review of 318 procedures in 210 patients. Postgraduate Medical Journal, 51, 564-566.

Lieberman, F. L. (1970). Functional renal failure in cirrhosis. Gastroenterology, 58, 108-110.

Liehr, H., Grün, M., Brunswig, D., and Sautter, Th. (1975). Endotoxaemia in liver cirrhosis: treatment with polymyxin B. Lancet, 1, 810-811.

McKay, D. G. (1973). Vessel wall and thrombogenesisendotoxin. Thrombosis et Diathesis Haemorrhagica, 29, 11-26.

Nies, A. S., Forsyth, R. P., Williams, H. E., and Melmon, K. L. (1968). Contribution of kinins to endotoxin shock in unanesthetised Rhesus monkeys. Circulation Research, 22, 155-164.

Nolan, J. P., and Ali, M. V. (1972). Effect of cholestyramine on endotoxin toxicity and absorption. American Journal of Digestive Disease, 17, 161-166.

Parbhoo, S. P., Ajdukiewicz, A., and Sherlock, S. (1974). Treatment of ascites by continuous ultrafiltration and reinfusion of protein concentrate. Lancet, 1, 949-952.

Ravin, H. A., Rowly, D., Jenkins, C., and Fine, J. (1960). On the absorption of bacterial endotoxin from the gastrointestinal tract of the normal and shocked animal. Journal of Experimental Medicine, 112, 783-792.

Reinhold, R. B., and Fine, J. (1971). A technique for quantitative measurement of endotoxin in human plasma. Proceedings of the Society for Experimental Biology and Medicine, 137, 334-340.

Rodés, J., Bosch, J., and Arroyo, V. (1975). Clinical types and drug therapy of renal impairment in cirrhosis. Postgraduate Medical Journal, 51, 492-497.

Summerskill, W. H. J. (1966). Hepatic failure and the kidney. Gastroenterology, 51, 94-107.

Tamakuma, S., Rojas-Corona, R., Cuevas, P., and Fine, J. (1971). Demonstration of a lethal endotoxemia of intestinal origin in refractory non-septic shock. Annals of Surgery, 173, 219-224.

Vesin, P. (1962). Late functional renal failure in cirrhosis with ascites: pathophysiology, diagnosis and treatment. International Association for the Study of the Liver: Aktuelle Probleme der Hepatologie, p. 98. Edited by G. A. Martini. Thieme: Stuttgart.

Wilkinson, S. P., Arroyo, V., Gazzard, B. G., Moodie, H., and Williams, R. (1974). Relation of renal impairment and haemorrhagic diathesis to endotoxaemia in fulminant hepatic failure. Lancet, 1, 521-524.

Wilkinson, S. P., Portmann, B., Hurst, D., and Williams, R. (1975). Pathogenesis of renal failure in cirrhosis and fulminant hepatic failure. Postgraduate Medical Journal, 51, 503-505.

Yin, E. T., Galanos, C., Kinsky, S., Bradshaw, R. A., Wessler, S., Lüderitz U., and Sarmiento, H. E. (1972). Picogram-sensitive assay for endotoxin: gelation of Limulus polyphemus blood cell lysate induced by purified lipopolysaccharides and lipid A from Gram-negative bacteria. Biochimica et Biophysica Acta, 261, 284-289. 